\title{
Self-Reported Disability in Adults with Severe Obesity
}

\author{
I. Kyrou, ${ }^{1}$ G. Osei-Assibey, ${ }^{1}$ N. Williams, ${ }^{2}$ R. Thomas, ${ }^{2}$ L. Halder, ${ }^{1}$ S. Taheri, ${ }^{3}$ \\ P. Saravanan, ${ }^{1}$ and S. Kumar ${ }^{1}$ \\ ${ }^{1}$ WISDEM, University Hospital Coventry and Warwickshire, Clinical Sciences Research Institute, Warwick Medical School, \\ University of Warwick, Coventry CV2 2DX, UK \\ ${ }^{2}$ Health, Work and Wellbeing Directorate, Department for Work and Pensions, London SW1H 9NA, UK \\ ${ }^{3}$ Birmingham Heartlands Hospital, Heart of England NHS Foundation Trust, Birmingham B9 5SS, UK \\ Correspondence should be addressed to I. Kyrou, I.Kyrou@warwick.ac.uk
}

Received 10 July 2011; Accepted 18 August 2011

Academic Editor: Terry Huang

Copyright () 2011 I. Kyrou et al. This is an open access article distributed under the Creative Commons Attribution License, which permits unrestricted use, distribution, and reproduction in any medium, provided the original work is properly cited.

Self-reported disability in performing daily life activities was assessed in adults with severe obesity (BMI $\left.\geq 35 \mathrm{~kg} / \mathrm{m}^{2}\right) \mathrm{using}$ the Health Assessment Questionnaire (HAQ). 262 participants were recruited into three BMI groups: Group I: $35-39.99 \mathrm{~kg} / \mathrm{m}^{2}$; Group II: $40-44.99 \mathrm{~kg} / \mathrm{m}^{2}$; Group III: $\geq 45.0 \mathrm{~kg} / \mathrm{m}^{2}$. Progressively increasing HAQ scores were documented with higher BMI; Group I HAQ score: 0.125 (median) (range: 0-1.75); Group II HAQ score: 0.375 (0-2.5); Group III HAQ score: 0.75 (0-2.65) (Group III versus II $P<0.001$; Group III versus I $P<0.001$; Group II versus I $P=0.004)$. HAQ score strongly correlated with BMI and age. Nearly three-fourths of the study participants reported some degree of disability (HAQ score $>0$ ). The prevalence of this degree of disability increased with increasing BMI and age. It also correlated to type 2 diabetes, metabolic syndrome, and clinical depression, but not to gender. Our data suggest that severe obesity is associated with self-reported disability in performing common daily life activities, with increasing degree of disability as BMI increases over $35 \mathrm{~kg} / \mathrm{m}^{2}$. Functional assessment is crucial in obesity management, and establishing the disability profiles of obese patients is integral to both meet the specific healthcare needs of individuals and develop evidence-based public health programs, interventions, and priorities.

\section{Introduction}

Obesity is the most frequent metabolic disease worldwide and can progressively lead to a spectrum of comorbidities, including type 2 diabetes, hypertension, dyslipidaemia, cardiovascular disease, liver dysfunction, and osteoarthritis [13]. Preventing obesity-related co-morbidity relies on effective weight loss interventions; however, it is becoming evident that there is also a further need to focus on the daily living and well-being of obese patients. Obesity is still associated with high early mortality, but advances in the treatment of cardiovascular risk factors and acute coronary syndromes are now offering better cardioprotection options and prolong life expectancy [4]. Current data support the notion that in developed societies an increasing number of obese patients are expected to live more than previously estimated, despite failing to reduce their body weight $[4,5]$.
Furthermore, demographic and epidemiological projections predict growing and progressively ageing obese populations in the Western world [6-8]. These populations are expected to exhibit an escalating burden of obesity-related disease, particularly regarding complications which were previously underestimated or underexpressed due to earlier mortality, such as mobility problems and disability [9].

Longstanding and/or progressive obesity can eventually impair the physical ability of the patient to function in everyday life. Obesity-associated disability has been shown to correlate with body mass index (BMI) and the presence of comorbidities [4, 10-13]. Difficulty to perform simple everyday tasks (e.g., walking, climbing steps, driving, and dressing) may complicate the daily life of obese patients to the extent of inability to engage in usual social activities and employment [4]. The consequent impact on quality of life is devastating and may lead to a vicious cycle where 
obesity progressively causes physical inactivity, functional limitations, and mental distress (e.g., anxiety, depression) and vice versa $[14,15]$.

Furthermore, the economic burden posed by obesityrelated disability on healthcare systems is alarming with reports suggesting that relative medical spending for the obese may be up to $100 \%$ higher than for normal-weight adults [16-18]. Evidence from the World Health Report shows that overweight and obesity is responsible for $8-15 \%$ of disability-adjusted life years lost in Europe and North America [19]. Notably, data from the National Longitudinal Survey of Youth in the USA indicate that being obese raises the probability of receiving disability income by 6.92 percentage points for men and by 5.64 percentage points for women, which is the equivalent to the effect of losing 15.9 and 16.7 years of education, respectively $[16,20]$.

Investigating the relationship between obesity and disability, identifying individuals at greater risk and improving their functional capacity are increasingly recognised as important steps in the care of obese patients. We present an observational study aimed to explore associations between increasing BMI and self-reported disability in adults with severe obesity.

\section{Patients and Methods}

The study cohort was recruited from adults with BMI $\geq 35 \mathrm{~kg} / \mathrm{m}^{2}$ followed at specialist outpatient obesity clinics at the Warwickshire Institute of Diabetes, Endocrinology and Metabolism (WISDEM, University Hospitals of Coventry and Warwickshire NHS Trust) and at the Birmingham Heartlands Hospital (Heart of England NHS Foundation Trust). Exclusion criteria included obesity secondary to endocrine or systemic disease (e.g., Cushing's syndrome) and disability attributed to systemic disease other than obesity (e.g., rheumatoid arthritis, neurological disorders) or to previous injuries/accidents. Patients with disability due to further secondary complications of cardiometabolic disease (e.g., diabetic foot ulcers, symptomatic diabetic neuropathy, Charcot's arthropathy, symptomatic ischemic heart disease, and heart failure) were also excluded. The study was approved by the local ethics committee, and all participants provided informed consent. A total of 262 patients (183 females/79 males; mean age: $44.9 \pm 10.5$ years) completed the study questionnaire, and all data were collected according to protocol, including demographic and comorbidity data obtained from reviewing the patients' medical charts.

\subsection{Assessments}

2.1.1. Anthropometry. Body weight and height were measured at the outpatient obesity clinics in participants without shoes and heavy clothing. Weight was measured to the nearest $0.5 \mathrm{~kg}$ using a digital platform scale suitable for morbidly obese patients with a capacity of $300 \mathrm{~kg}$ (Seca 675, Seca, Hamburg, Germany). The Harpenden stadiometer was used to measure height to the nearest $0.1 \mathrm{~cm}$. BMI was calculated as body weight in kilograms divided by the square of the height in meters. For the purposes of this study participants were categorized into three BMI groups: Group I: $35-39.99 \mathrm{~kg} / \mathrm{m}^{2}$; Group II: $40-44.99 \mathrm{~kg} / \mathrm{m}^{2}$; Group III: $\geq 45.0 \mathrm{~kg} / \mathrm{m}^{2}$.

2.1.2. Health Assessment Questionnaire. The Stanford Health Assessment Questionnaire (HAQ) was used as a validated self-report measure of functional ability in daily life [21, 22]. The HAQ has been widely applied in research, and, although initially developed for use in rheumatology, it is considered a generic instrument rather than disease specific [22-24]. Briefly, disability is assessed by the HAQ disability index through 20 questions regarding the degree of difficulty in performing two or three specific activities in eight distinct categories. These categories are (1) dressing and grooming; (2) arising; (3) eating; (4) walking; (5) hygiene; (6) reach; (7) grip; (8) common daily activities. Four possible grades of difficulty are provided for answering each question, which are rated as "Without ANY Difficulty," "With SOME Difficulty," "With MUCH Difficulty," and "UNABLE To do" and are assigned a score of $0,1,2$, and 3, respectively. In addition, each category has a companion variable for aids/devices that documents if any type(s) of assistance is required for the respective daily activities. For these variables the patient is also asked to report whether he/she (1) needs no assistance; (2) uses a special device in his/her daily activities; (3) usually needs help from another person; or (4) usually needs both a special device and help from another person. A complete copy of the instrument and instructions on its use can be downloaded from http://aramis.stanford.edu. Provided that the participant has given answers for at least six categories, the average score of the completed categories determines the final HAQ score (Standard HAQ disability index score) which ranges from 0 to 3 ( 0 : no functional disability; 3: worst functional disability). Because healthy individuals consistently score zero on the HAQ [23], for the purposes of this study participants were also divided based on their final HAQ score to patients with no disability (HAQ score: 0 ) and patients with at least some degree of disability (HAQ score $>0)$.

\subsubsection{Self-Reported Difficulty in Standing and Walking. Inde} -pendently of the HAQ, participants were also asked about having difficulty: (1) in standing unaided for 2 to 3 minutes and (2) in walking more than 100 metres (if necessary with aids). Four possible grades of difficulty were provided for each of these two questions: "Without ANY Difficulty," "With SOME Difficulty," "With MUCH Difficulty," and "UNABLE To do," assigned a score of 0, 1, 2, and 3, respectively. For the purposes of this aspect of the study participants were dichotomised based on their responses regarding difficulty in standing and in walking more than 100 metres to either having no difficulty $($ score $=0)$ or having at least some difficulty ( score $>0$ ).

2.2. Statistical Analysis. The Statistical Package for the Social Sciences, SPSS, version 17.0 (SPSS Inc, Chicago, IL, USA) was used to analyze data. Results are expressed as percentage, mean \pm standard deviation or median (range). The Kolmogorov-Smirnov and the Shapiro-Wilk tests were 
used to determine whether each study variable had a normal distribution. Based on these tests, BMI and HAQ score distributions in this study were nonparametric. Thus, comparisons between study groups were performed with the Mann-Whitney $U$-test or the Kruskal-Wallis test, and correlations were tested by the Spearman's rank correlation coefficient. Prevalence rates of disability between patient groups were compared and tested for statistical significance by chi-square test. Logistic regression was applied to test the relation of disability with various covariates. A $P$ value of $<0.05$ was considered statistically significant.

\section{Results}

A total of 262 obese patients consented to participate in the study out of 434 patients that were invited to participate, representing a $60 \%$ response rate ( 183 female (F) and 79 male (M) patients; with approximately $61.5 \%$ and $58 \%$ response rate in women and men, resp.). Mean age of the study participants was $44.9 \pm 10.5$ years (women: $44.2 \pm 10.5$ years; men: $46.7 \pm 10.4$ years), with a mean BMI of $46.84 \pm$ $8.5 \mathrm{~kg} / \mathrm{m}^{2}$ (women: $46.4 \pm 8.1 \mathrm{~kg} / \mathrm{m}^{2}$; men: $47.8 \pm 9.2 \mathrm{~kg} / \mathrm{m}^{2}$ ). Approximately $35 \%$ of the participants had type 2 diabetes (T2DM), 37\% metabolic syndrome (metabolic syndrome as defined by the International Diabetes Federation definition, IDF, [25]), and $29 \%$ a diagnosis of clinical depression. Patient characteristics and distribution of participants by BMI group, gender and presence of comorbidities are presented in Table 1.

A non-parametric distribution was noted for BMI and HAQ score in the study cohort. HAQ scores by BMI group, gender, and comorbidities are presented in Table 2. The median value of the HAQ score for the entire study cohort was 0.375 (range: $0-2.65$ ) and an increase in the HAQ score was noted with increasing BMI. The Kruskal-Wallis test revealed statistically significant difference in the HAQ score between the three BMI groups $(P<0.001)$. The MannWhitney test was used to compare HAQ scores between the different pairs of BMI groups showing that (1) Group II had a significantly higher HAQ score compared to Group I $(P=0.004)$; (2) Group III had a significantly higher HAQ score compared to Group I $(P<0.001)$; (3) Group III had a significantly higher HAQ score compared to Group II $(P<0.001)$ (Figure 1). Spearman's correlation showed that there was a significant correlation between HAQ score and BMI $(r=0.420, P<0.001)$, as well as between HAQ score and age $(r=0.208, P=0.001)$. After controlling for age, the correlation between HAQ score and BMI remained significant $(P<0.001)$.

Healthy individuals consistently score zero on the HAQ [23], thus, an analysis was performed by dichotomizing the study cohort based on the HAQ score to patients with no disability (HAQ score: 0 ) and patients with at least some degree of disability (HAQ score $>0$ ). Of all study participants, $72.5 \%$ had HAQ scores higher than zero, reporting at least a mild degree of difficulty in activities of daily living. The prevalence rates of this degree of disability (HAQ score $>0$ ) between the different patient groups were compared and tested for statistical significance by chi-square test. Based

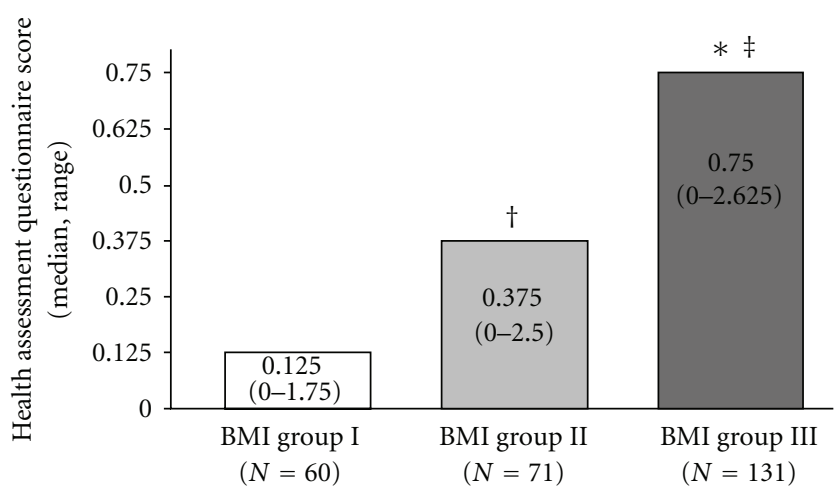

FIGURE 1: Health Assessment Questionnaire (HAQ) scores (median, range) across the three body mass index (BMI) study groups (Group I: $35-39.99 \mathrm{~kg} / \mathrm{m}^{2}$; Group II: $40-44.99 \mathrm{~kg} / \mathrm{m}^{2}$; Group III: $\left.\geq 45.0 \mathrm{~kg} / \mathrm{m}^{2}\right)$. * Group III versus Group I $(P<0.001) ;{ }^{\ddagger}$ Group III versus Group II $(P<0.001) ;{ }^{\dagger}$ Group II versus Group I $(P=0.004)$.

on Pearson chi-square test, the prevalence rate of disability (HAQ score > 0) was related to BMI and to the presence of T2DM, metabolic syndrome, and depression, while it was not related to gender. Indeed, the prevalence rate of disability (HAQ score > 0) was significantly higher: (1) among participants with a higher BMI $(51.7 \%$ for Group I versus $66.2 \%$ for Group II versus $85.5 \%$ for Group III, $P<0.001$, Table 3); (2) among participants with T2DM (81.5\% versus $67.6 \%$ in nondiabetic participants, $P=0.016$ ); (3) among participants with metabolic syndrome $(79.6 \%$ versus $68.3 \%$ in participants without metabolic syndrome, $P=0.047)$; (4) among participants with clinical depression $(85.75 \%$ versus $67 \%$ in nondepressed participants, $P=0.002$ ). Table 3 also presents the distribution of participants across the three BMI study groups when the HAQ score is categorized into 4 grades: (1) HAQ: 0 (no disability); (2) HAQ: 0.1-0.99 (mild to moderate difficulty); (3) HAQ: 1-1.99 (moderate to severe disability); (4) HAQ: 2-3 (severe to very severe disability). Logistic regression modelling in this study cohort showed that BMI was associated with an odds ratio (OR) of 1.128 (95\% CI: $1.075-1.184 ; P<0.001$ ) for disability (HAQ score $>0$ ) adjusted for age and with an OR of 1.127 (95\% CI: 1.073-1.185; $P<0.001$ ) adjusted for both age and depression. T2DM and metabolic syndrome when entered as covariates into the logistic regression model did not have a statistically significant effect to the model. These obesityrelated comorbidities were considered intermediaries in and not confounders to the association between increased BMI and disability, since based on the exclusion criteria of this study, patients with disability attributed to further secondary complications of cardio-metabolic disease (e.g., diabetic foot ulcers, symptomatic diabetic neuropathy, Charcot's arthropathy, symptomatic ischemic heart disease, and heart failure) were excluded.

Finally, the prevalence rates of having at least some difficulty in standing (score $>0$ ) and in walking more than 100 meters (score $>0$ ) between the different patient groups 
TABLE 1: Selected patient characteristics and patient distribution by body mass index (BMI) group, gender, and presence of comorbidities.

\begin{tabular}{|c|c|c|c|c|}
\hline \multicolumn{5}{|c|}{ BMI group } \\
\hline Characteristics & $\begin{array}{c}\text { Group I } \\
35-39.99 \mathrm{~kg} / \mathrm{m}^{2} \\
(N=60)\end{array}$ & $\begin{array}{c}\text { Group II } \\
40-44.99 \mathrm{~kg} / \mathrm{m}^{2} \\
(N=71)\end{array}$ & $\begin{array}{l}\text { Group III } \\
\geq 45 \mathrm{~kg} / \mathrm{m}^{2} \\
(N=131)\end{array}$ & Total $(N=262)$ \\
\hline \multicolumn{5}{|l|}{ BMI $\left(\mathrm{kg} / \mathrm{m}^{2}\right)$} \\
\hline Range & $35.1-39.8$ & $40.2-44.9$ & $45.1-77.9$ & $35.1-77.9$ \\
\hline Median & 37.93 & 42.53 & 51.07 & 45.01 \\
\hline Mean (SD) & $37.68(1.42)$ & $42.55(1.39)$ & $53.37(7.1)$ & $46.84(8.5)$ \\
\hline \multicolumn{5}{|l|}{ Age (years) } \\
\hline Range & $22-69$ & $22-75$ & $21-66$ & $21-75$ \\
\hline Median & 45 & 47 & 44 & 45 \\
\hline Mean (SD) & $46(9.9)$ & $46(10.8)$ & $43.9(10.6)$ & $44.9(10.5)$ \\
\hline \multicolumn{5}{|l|}{ Gender } \\
\hline \multirow{2}{*}{ Men } & 17 & 18 & 44 & 79 \\
\hline & [28.33\%] [6.48\%] & [25.35\%] [6.87\%] & [33.59\%] [16.8\%] & [30.15\%] \\
\hline \multirow{2}{*}{ Women } & 43 & 53 & 87 & 183 \\
\hline & [71.67\%] [16.41\%] & [74.64\%] [20.23\%] & {$[66.41 \%][33.20 \%]$} & {$[69.85 \%]$} \\
\hline \multicolumn{5}{|l|}{ T2DM } \\
\hline \multirow{2}{*}{ No } & 38 & 46 & 86 & 170 \\
\hline & {$[63.33 \%][14.50 \%]$} & {$[64.79 \%][17.55 \%]$} & {$[65.64 \%][32.82 \%]$} & {$[64.88 \%]$} \\
\hline \multirow{2}{*}{ Yes } & 22 & 25 & 45 & 92 \\
\hline & {$[36.66 \%][8.39 \%]$} & [35.21\%] [9.54\%] & {$[34.35 \%][17.17 \%]$} & {$[35.12 \%]$} \\
\hline \multicolumn{5}{|l|}{ MetS } \\
\hline \multirow{2}{*}{ No } & 39 & 43 & 82 & 164 \\
\hline & [65\%] [14.88\%] & {$[60.56 \%][16.41 \%]$} & {$[62.59 \%][31.29 \%]$} & [62.59\%] \\
\hline \multirow{2}{*}{ Yes } & 21 & 28 & 49 & 98 \\
\hline & [35\%] [8.02\%] & [39.44\%] [10.69\%] & {$[37.40 \%][18.70 \%]$} & [37.41\%] \\
\hline \multicolumn{5}{|l|}{ Depression } \\
\hline \multirow{2}{*}{ No } & 47 & 51 & 87 & 185 \\
\hline & {$[78.33 \%][17.93 \%]$} & {$[71.83 \%][19.46 \%]$} & {$[66.41 \%][33.20 \%]$} & {$[70.61 \%]$} \\
\hline \multirow{2}{*}{ Yes } & 13 & 20 & 44 & 77 \\
\hline & {$[21.66 \%][4.96 \%]$} & [28.17\%] [7.64\%] & [33.59\%] [16.79\%] & [29.39\%] \\
\hline
\end{tabular}

Figures in brackets indicate $\%$ of each BMI category and \% of total cohort, respectively.

SD: standard deviation; T2DM: type 2 diabetes mellitus; MetS: metabolic syndrome.

were also compared and tested for statistical significance. Based on Pearson chi-square test, the prevalence rate of difficulty in standing (score $>0$ ) was related to BMI and to the presence of T2DM, while it was not related to gender, metabolic syndrome, and depression. Thus, the prevalence rate of having at least some difficulty in standing was significantly higher: (1) among participants with a higher BMI $(8.3 \%$ for Group I, $27.1 \%$ for Group II, $24.8 \%$ for Group III, $P=0.016)$; (2) among participants with T2DM $(30.8 \%$ versus $16.7 \%$ in non-diabetic participants, $P=$ 0.008). Furthermore, the prevalence rate of difficulty in walking more than 100 meters (score $>0$ ) was related to BMI and to the presence of depression, while it was not related to gender, T2DM, and metabolic syndrome. Indeed, the prevalence rate of having at least some difficulty in walking more than 100 meters was significantly higher: (1) among participants with a higher BMI (18.6\% for Group I,
$44.1 \%$ for Group II, 53.2\% for Group III, $P<0.001$ ); (2) among participants with depression (58.6\% versus $36.5 \%$ in nondepressed participants, $P=0.001$ ).

\section{Discussion}

The primary objective of this study was to explore associations between obesity and self-reported disability in adults with $\mathrm{BMI} \geq 35 \mathrm{~kg} / \mathrm{m}^{2}$. The data from our cohort of patients with severe obesity showed that self-reported disability, as expressed by the HAQ score, correlated with BMI, age, and the presence of T2DM, metabolic syndrome, and clinical depression. This finding agrees with data from the literature that have documented the burden of disability in general and obese populations, as well as in various other patient groups [26-39]. 
TABle 2: Health Assessment Questionnaire (HAQ) disability index scores by body mass index (BMI) group, gender, and comorbidities.

\begin{tabular}{|c|c|c|c|c|}
\hline \multirow{3}{*}{ Characteristics } & \multicolumn{3}{|c|}{ BMI group } & \multirow{3}{*}{ Total } \\
\hline & Group I & Group II & Group III & \\
\hline & $35-39.99 \mathrm{~kg} / \mathrm{m}^{2}$ & $40-44.99 \mathrm{~kg} / \mathrm{m}^{2}$ & $\geq 45 \mathrm{~kg} / \mathrm{m}^{2}$ & \\
\hline \multicolumn{5}{|l|}{ All patients } \\
\hline$N[\%]$ & $60[22.9 \%]$ & $71[27.1 \%]$ & $131[50 \%]$ & $262[100 \%]$ \\
\hline \multicolumn{5}{|l|}{ HAQ: } \\
\hline Range & $0-1.75$ & $0-2.5$ & $0-2.625$ & $0-2.65$ \\
\hline Median & 0.125 & 0.375 & 0.75 & 0.375 \\
\hline Mean (SD) & $0.202(0.29)$ & $0.515(0.61)$ & $0.842(0.67)$ & $0.607(0.64)$ \\
\hline \multicolumn{5}{|l|}{ Men } \\
\hline$N[\%]$ & $17[6.48 \%]$ & $18[6.87 \%]$ & 44 [16.8\%] & 79 [30.15\%] \\
\hline \multicolumn{5}{|l|}{ HAQ: } \\
\hline Range & $0-0.625$ & $0-2.125$ & $0-2.5$ & $0-2.5$ \\
\hline Median & 0.125 & 0.3125 & 0.875 & 0.5 \\
\hline Mean (SD) & $0.206(0.22)$ & $0.388(0.55)$ & $0.954(0.63)$ & $0.664(0.64)$ \\
\hline \multicolumn{5}{|l|}{ Women } \\
\hline$N[\%]$ & 43 [16.41\%] & 53 [20.23\%] & 87 [33.20\%] & $183[69.85 \%]$ \\
\hline \multicolumn{5}{|l|}{ HAQ: } \\
\hline Range & $0-1.75$ & $0-2.5$ & $0-2.625$ & $0-2.65$ \\
\hline Median & 0.0 & 0.375 & 0.625 & 0.375 \\
\hline Mean (SD) & $0.2(0.32)$ & $0.559(0.63)$ & $0.785(0.69)$ & $0.582(0.65)$ \\
\hline \multicolumn{5}{|l|}{ Non T2DM } \\
\hline$N[\%]$ & $38[14.50 \%]$ & $46[17.55 \%]$ & 86 [32.82\%] & $170[64.88 \%]$ \\
\hline \multicolumn{5}{|l|}{ HAQ: } \\
\hline Range & $0-0.75$ & $0-2.5$ & $0-2.5$ & $0-2.5$ \\
\hline Median & 0.0 & 0.25 & 0.625 & 0.3125 \\
\hline Mean (SD) & $0.134(0.2)$ & $0.407(0.54)$ & $0.729(0.65)$ & $0.509(0.6)$ \\
\hline \multicolumn{5}{|l|}{ T2DM } \\
\hline$N[\%]$ & $22[8.39 \%]$ & 25 [9.54\%] & 45 [17.17\%] & $92[35.12 \%]$ \\
\hline \multicolumn{5}{|l|}{ HAQ: } \\
\hline Range & $0-1.75$ & $0-2.0$ & $0-2.625$ & $0-2.625$ \\
\hline Median & 0.375 & 0.5 & 1.0 & 0.5625 \\
\hline Mean (SD) & $0.318(0.38)$ & $0.715(0.71)$ & $1.058(0.66)$ & $0.788(0.68)$ \\
\hline \multicolumn{5}{|l|}{ Non MetS } \\
\hline$N[\%]$ & 39 [14.88\%] & 43 [16.41\%] & 82 [31.29\%] & $164[62.59 \%]$ \\
\hline \multicolumn{5}{|l|}{ HAQ: } \\
\hline Range & $0-1.75$ & $0-2.5$ & $0-2.25$ & $0-2.5$ \\
\hline Median & 0.0 & 0.25 & 0.5625 & 0.375 \\
\hline Mean (SD) & $0.163(0.31)$ & $0.424(0.54)$ & $0.698(0.61)$ & $0.499(0.58)$ \\
\hline \multicolumn{5}{|l|}{ MetS } \\
\hline$N[\%]$ & $21[8.02 \%]$ & 28 [10.69\%] & 49 [18.70\%] & $98[37.41 \%]$ \\
\hline \multicolumn{5}{|l|}{ HAQ: } \\
\hline Range & $0-0.625$ & $0-2.0$ & $0-2.625$ & $0-2.625$ \\
\hline Median & 0.375 & 0.5 & 1.0 & 0.5625 \\
\hline Mean (SD) & $0.273(0.23)$ & $0.656(0.7)$ & $1.084(0.7)$ & $0.788(0.71)$ \\
\hline \multicolumn{5}{|l|}{ Nondepressed } \\
\hline$N[\%]$ & 47 [17.93\%] & 51 [19.46\%] & 87 [33.2\%] & $185[70.61 \%]$ \\
\hline \multicolumn{5}{|l|}{ HAQ: } \\
\hline Range & $0-0.75$ & $0-2.5$ & $0-2.375$ & $0-2.5$ \\
\hline Median & 0.0 & 0.25 & 0.5 & 0.375 \\
\hline Mean (SD) & $0.154(0.2)$ & $0.485(0.63)$ & $0.686(0.61)$ & $0.495(0.58)$ \\
\hline
\end{tabular}


TABle 2: Continued.

\begin{tabular}{|c|c|c|c|c|}
\hline \multirow{3}{*}{ Characteristics } & \multicolumn{3}{|c|}{ BMI group } & \multirow{3}{*}{ Total } \\
\hline & Group I & Group II & Group III & \\
\hline & $35-39.99 \mathrm{~kg} / \mathrm{m}^{2}$ & $40-44.99 \mathrm{~kg} / \mathrm{m}^{2}$ & $\geq 45 \mathrm{~kg} / \mathrm{m}^{2}$ & \\
\hline \multicolumn{5}{|l|}{ Depression } \\
\hline$N[\%]$ & $13[4.96 \%]$ & $20[7.64 \%]$ & 44 [16.79\%] & 77 [29.39\%] \\
\hline \multicolumn{5}{|l|}{ HAQ: } \\
\hline Range & $0-1.75$ & $0-2.125$ & $0-2.625$ & $0-2.625$ \\
\hline Median & 0.375 & 0.5 & 1.25 & 0.75 \\
\hline Mean (SD) & $0.375(0.47)$ & $0.593(0.59)$ & $1.150(0.7)$ & $0.875(0.71)$ \\
\hline
\end{tabular}

Figures in brackets indicate \% of total cohort.

SD: standard deviation; T2DM: type 2 diabetes mellitus; MetS: metabolic syndrome.

TABle 3: Prevalence rates of degrees of disability based on the Health Assessment Questionnaire (HAQ) score across the three body mass index (BMI) study groups (no disability (HAQ score: 0); at least some degree of disability (HAQ score > 0); mild to moderate difficulty in performing daily life activities (HAQ score: $0.1-0.99$ ); moderate to severe disability (HAQ score: $1-1.99$ ); severe to very severe disability (HAQ score: 2-3).

\begin{tabular}{|c|c|c|c|c|}
\hline \multirow[b]{2}{*}{ HAQ grade } & \multicolumn{3}{|c|}{ BMI group } & \multirow[b]{2}{*}{ Total $(N=262)$} \\
\hline & $\begin{array}{c}\text { Group I } \\
35-39.99 \mathrm{~kg} / \mathrm{m}^{2} \\
(N=60)\end{array}$ & $\begin{array}{c}\text { Group II } \\
40-44.99 \mathrm{~kg} / \mathrm{m}^{2} \\
(N=71)\end{array}$ & $\begin{array}{l}\text { Group III } \\
\geq 45 \mathrm{~kg} / \mathrm{m}^{2} \\
(N=131)\end{array}$ & \\
\hline \multicolumn{5}{|l|}{ HAQ: 0} \\
\hline$N$ & 29 & 24 & 19 & 72 \\
\hline \% within HAQ grade & $40.3 \%$ & $33.3 \%$ & $26.4 \%$ & $100.0 \%$ \\
\hline$\%$ within BMI group & $48.3 \%$ & $33.8 \%$ & $14.5 \%$ & $27.5 \%$ \\
\hline$\%$ of total & $11.1 \%$ & $9.2 \%$ & $7.3 \%$ & $27.5 \%$ \\
\hline \multicolumn{5}{|l|}{ HAQ: $>0$} \\
\hline$N$ & 31 & 47 & 112 & 190 \\
\hline \% within HAQ grade & $16.3 \%$ & $24.7 \%$ & $58.9 \%$ & $100.0 \%$ \\
\hline \% within BMI group & $51.7 \%$ & $66.2 \%$ & $85.5 \%$ & $72.5 \%$ \\
\hline$\%$ of total & $11.8 \%$ & $17.9 \%$ & $42.7 \%$ & $72.5 \%$ \\
\hline \multicolumn{5}{|l|}{ HAQ: 0.1-0.99 } \\
\hline$N$ & 30 & 33 & 60 & 123 \\
\hline \% within HAQ grade & $24.4 \%$ & $26.8 \%$ & $48.8 \%$ & $100.0 \%$ \\
\hline$\%$ within BMI group & $50.0 \%$ & $46.5 \%$ & $45.8 \%$ & $46.9 \%$ \\
\hline$\%$ of total & $11.5 \%$ & $12.6 \%$ & $22.9 \%$ & $46.9 \%$ \\
\hline \multicolumn{5}{|l|}{ HAQ: $1-1.99$} \\
\hline$N$ & 1 & 11 & 42 & 54 \\
\hline$\%$ within HAQ grade & $1.9 \%$ & $20.4 \%$ & $77.8 \%$ & $100.0 \%$ \\
\hline \% within BMI group & $1.7 \%$ & $15.5 \%$ & $32.1 \%$ & $20.6 \%$ \\
\hline$\%$ of total & $0.4 \%$ & $4.2 \%$ & $16.0 \%$ & $20.6 \%$ \\
\hline \multicolumn{5}{|l|}{ HAQ: 2-3 } \\
\hline$N$ & 0 & 3 & 10 & 13 \\
\hline$\%$ within HAQ grade & $0.0 \%$ & $23.1 \%$ & $76.9 \%$ & $100.0 \%$ \\
\hline \% within BMI group & $0.0 \%$ & $4.2 \%$ & $7.6 \%$ & $5.0 \%$ \\
\hline$\%$ of total & $0.0 \%$ & $1.1 \%$ & $3.8 \%$ & $5.0 \%$ \\
\hline
\end{tabular}

The mean HAQ score for our study population was 0.607 (95\% CI: $0.528-0.686)$ with a median value of 0.375 (range: 0-2.65). Krishnan et al. have reported normative values for the HAQ disability index in the general population in Finland, documenting a population mean HAQ score of
0.25 (95\% CI: $0.22-0.28$ ), with $32 \%$ of respondents having at least some disability (HAQ score > 0) [26]. Given that healthy individuals consistently score zero on the HAQ [23] and that the HAQ score distribution is not Gaussian, we also applied zero as a cut point for the HAQ score in order to 
dichotomize our study cohort into patients without disability and patients with at least some difficulty in activities of daily living. In this analysis, $72.5 \%$ of our study participants had HAQ scores higher than zero. This is in accord with the analysis of the data from Finland showing that within the studied general population, which included approximately $20 \%$ obese participants $\left(\mathrm{BMI}>30 \mathrm{~kg} / \mathrm{m}^{2}\right.$ ), individuals with $\mathrm{BMI} \leq 30 \mathrm{~kg} / \mathrm{m}^{2}$ had a significantly lower prevalence rate of disability compared with obese individuals (HAQ score > 0 : $28.4 \%$ versus $51.7 \%$ for nonobese and obese individuals, resp.) [26]. Of note, in our study the prevalence rate of disability (HAQ score > 0) was 51.7\% in Group I, 66.2\% in Group II, and $85.5 \%$ in Group III, further documenting a gradient of increasing self-reported disability as BMI increases over $35 \mathrm{~kg} / \mathrm{m}^{2}$. Indeed, comparing the HAQ score for the three study BMI groups, we found that Group III had significantly higher HAQ score compared with the other two groups, while Group II had also significantly higher HAQ score compared with Group I. The recognition of this gradient may be useful in clinical practice for identifying obese individuals with greater difficulty in performing everyday tasks and could also allow further stratification of patients in order to intensify interventions and prioritize the use of available healthcare resources.

It must be noted that different cut points can be used to define or categorize disability based on the HAQ disability index score $[40,41]$. HAQ scores up to 1 are generally considered to reflect mild to moderate difficulty in daily life activities, while scores between 1 and 2 represent moderate to severe disability, and scores of 2 to 3 indicate severe to very severe disability [40]. A study by Walter et al., exploring the effects of obesity on mortality and disability in the older population in The Netherlands, has used a cut point of 0.5 to define a participant as at least mildly disabled [27], as previously applied for participants in the Rotterdam study cohort [33]. The results of this study in older adults (age 55 years and older) also documented that BMI was related to self-reported disability, with more years lost to disability with increasing body weight, supporting our study findings. Of note, applying zero as a cut point for the HAQ score in the context of obesity provides a distinct measure to dichotomize patients for the presence of disability, which is not affected by the dispersion of the HAQ score within different BMI categories and hence may be suggested as a less controversial method than using any other cut-off value. Furthermore, this cut point can also be regarded as a treatment goal for weight loss interventions. Thus, a notion of recovery from obesity-related disability could be advocated similarly to remission/resolution of T2DM with weight loss. Interestingly, studies in patients with rheumatoid arthritis have documented that HAQ disability index scores needed to improve by approximately -0.22 units before participants stopped rating themselves as about the same (minimally clinically important difference) [41]. In patients with severe obesity, further research is required to evaluate at what extent weight loss is associated with clinically meaningful differences in physical functioning/disability scores and whether certain weight loss interventions (e.g., diet, exercise, cognitive behavioral therapy, pharmacotherapy, bariatric surgery, and their combinations) might differ regarding such functional/health status outcomes [42].

In addition to BMI, the HAQ score in our study also correlated with age, which is consistent with available data from the general population [26, 39]. However, in this study cohort no relation was noted between the HAQ score and gender, contrary to published evidence indicating that activities of daily living may be more affected in women, especially in older populations [27, 43-45]. This could be partly attributed to a referral bias of obese patients with higher disability independently of gender. Krishnan et al. also reported that disability among women increased at a faster rate compared to that among men and that women had a higher estimated mean HAQ score ( 0.28 versus 0.18 in men) [26]. Yet, also in this study, which included 1530 adults, this gender difference was no longer statistically significant after adjustment for age.

Finally, in our cohort of severely obese patients the HAQ score was related to the presence of T2DM, metabolic syndrome, and clinical depression. Central obesity is a prerequisite for the IDF metabolic syndrome definition [25], and T2DM is pathogenetically linked to obesity [46]. In addition, for the purposes of this study patients with disability due to secondary complications of T2DM and/or metabolic syndrome (e.g., diabetic foot ulcers, symptomatic diabetic neuropathy, Charcot's arthropathy, symptomatic ischemic heart disease, and heart failure) were excluded. Hence, these comorbidities were regarded as intermediaries in and not confounders to the association between increased BMI and disability and when entered as covariates into the logistic regression models of this study did not have a statistically significant effect. Contrary, the published data regarding the association between obesity and depression is less strong and mixed [47-51]. Therefore, depression was entered as a covariate in the applied logistic regression model which showed that, adjusted for both age and depression, BMI was associated with an OR of 1.127 (95\% CI: 1.0731.185; $P<0.001$ ) for disability (HAQ score $>0$ ).

\section{Limitations of the Study}

A limitation of this study is that the functional ability of participants was self-reported. However, the HAQ is a well-validated instrument, which is considered to accurately document the existing degree of disability and is widely applied in research. Furthermore, the HAQ can be regarded as a generic measure to quantify functional impairment, rather than disease specific for obesity. A similar validated and established obesity-specific instrument for self-reporting difficulty in daily life activities is currently lacking. On the other hand, a relative advantage of applying a generic measure is that it allows a degree of comparability between obtained results and available data from the general population and from patient groups with other diseases associated with disability.

In this study, a random sample of the outpatient population followed at our specialist obesity clinics was obtained, and the overall response rate was considered adequate. However, the nonresponse behaviour of severely 
obese patients attending an obesity clinic may not be random but, rather, informative. In this case, the group of nonresponders may have had either lower or higher HAQ scores compared with respondents, resulting in an overall disability rate for the study cohort, which would be either an over- or underestimation, respectively. Overestimation of the disability prevalence among patients followed at an obesity clinic may also result from a referral bias due to higher referring rates of patients with more complications from primary to secondary care. Conversely, under-estimation could result from a different referral bias due to earlier/prompt referrals of obese patients to secondary care in order to prevent obesity-related complications. Such limitations are relatively common in this type of research; however, among the strengths of our study is the accurate assessment of BMI for all participants, since these study data were not selfreported, but were obtained through standardized clinical measurements of body weight and height at the included clinics.

Finally, a cause and effect relationship between obesity and disability cannot be determined from this cross-sectional study, and large, prospective studies are required to establish such a relationship.

\section{Conclusion}

Our study focuses on associations between severe obesity and functional limitations in activities of daily living. This aspect of the disease has not received adequate attention, despite robust evidence showing a growing burden of obesity-related disability. Almost three quarters of our study population reported at least some difficulty in performing daily life activities, and higher disability was documented with increasing BMI, age, and presence of T2DM, metabolic syndrome, and clinical depression. Such data can compliment current systems of obesity classification which are mainly based on anthropometric measures and do not offer direct information on comorbid disease. Indeed, clinical and functional staging systems for obesity are required to describe the morbidity and functional limitations associated with increased BMI in order to improve decision making in the clinical practice [52]. For this purpose, disability assessment should be an integral part of obesity management, including patients that have failed to achieve significant weight loss. Thus, healthcare providers would be able to provide recommendations based on the functional status of patients in order to increase regular physical activity according to their abilities and avoid complete inactivity. For instance, exercises that mainly promote flexibility and functionality could be recommended to severely obese individuals in order to improve their ability to perform common daily life activities and accommodate their work-specific functional needs (e.g., focus on improving coordination, balance, motion rage, cardiovascular, and muscle fitness). Furthermore, data on obesity-related disability could support practical strategies to create an obese friendly workplace (e.g., appropriate chairs and personal protective equipment) and built environment (e.g., easy access and use not only of medical facilities but also of services such as public transportation systems, community centres, parks, and green spaces) in order to encourage physical activity, work, and social engagement. Finally, potentially contributing factors such as depression, anxiety, low self-esteem, and social exclusion should be also identified and addressed in the context of a holistic approach to combat obesity-related disability and advance the care of obese patients.

\section{Conflict of Interests}

Professor S. Kumar declares support from Novo Nordisk, AstraZeneca, and GlaxoSmithKline for research and honoraria for lectures and from Eli Lilly for research consultancy. Dr. N. Williams and Dr. R. Thomas are employed by the Department for Work and Pensions (DWP), UK. Dr. I. Kyrou, Dr. G. Osei-Assibey, Mrs L. Halder, Dr. S. Taheri and Dr. P. Saravanan have no conflict of interests to declare.

\section{Acknowledgments}

The authors gratefully acknowledge funding support for this study from the Department for Work and Pensions (DWP), UK, and the assistance of Dr. Helen Watts of the DWP in the development of this study. Dr. S. Taheri receives research funding from the National Institute of Health Research (NIHR) as part of the Collaboration for Leadership in Applied Health Research and Care (CLAHRC).

\section{References}

[1] W. P. James, "The epidemiology of obesity: the size of the problem," Journal of Internal Medicine, vol. 263, no. 4, pp. 336352, 2008.

[2] P. Kopelman, "Health risks associated with overweight and obesity," Obesity Reviews, vol. 8, supplement 1, pp. 13-17, 2007.

[3] I. Kyrou and M. O. Weickert, "Clinical problems caused by obesity," in Obesity, M. Tschöp, Ed., MDTEXT, Dartmouth, Mass, USA, 2010, http://www.endotext.org/obesity/ obesity13/obesityframe13.htm.

[4] D. E. Alley and V. W. Chang, "The changing relationship of obesity and disability, 1988-2004," JAMA, vol. 298, no. 17, pp. 2020-2027, 2007.

[5] S. L. Reynolds, Y. Saito, and E. M. Crimmins, "The impact of obesity on active life expectancy in older American men and women," Gerontologist, vol. 45, no. 4, pp. 438-444, 2005.

[6] Centers for Disease Control and Prevention, "Public health and aging: trends in aging-United States and worldwide," JAMA, vol. 11, pp. 1371-1373, 2003.

[7] D. E. Arterburn, P. K. Crane, and S. D. Sullivan, "The coming epidemic of obesity in elderly Americans," Journal of the American Geriatrics Society, vol. 52, no. 11, pp. 1907-1912, 2004.

[8] I. Kyrou and C. Tsigos, "Obesity in the elderly diabetic patient: is weight loss beneficial?” Diabetes Care, vol. 32, pp. S403S409, 2009.

[9] E. W. Gregg and J. M. Guralnik, "Is disability obesity's price of longevity?” JAMA, vol. 298, no. 17, pp. 2066-2067, 2007.

[10] D. K. Houston, J. Stevens, and J. Cai, "Abdominal fat distribution and functional limitations and disability in a biracial cohort: the Atherosclerosis Risk in Communities 
Study," International Journal of Obesity, vol. 29, no. 12, pp. 1457-1463, 2005.

[11] U. E. Larsson and E. Mattsson, "Functional limitations linked to high body mass index, age and current pain in obese women," International Journal of Obesity and Related Metabolic Disorders, vol. 25, no. 6, pp. 893-899, 2001.

[12] R. Sturm, J. S. Ringel, and T. Andreyeva, "Increasing obesity rates and disability trends," Health Affairs, vol. 23, no. 2, pp. 199-205, 2004.

[13] K. F. Ferraro, Y. P. Su, R. J. Gretebeck, D. R. Black, and S. F. Badylak, "Body mass index and disability in adulthood: a 20year panel study," American Journal of Public Health, vol. 92, no. 5, pp. 834-840, 2002.

[14] K. R. Fontaine and I. Barofsky, "Obesity and health-related quality of life," Obesity Reviews, vol. 2, no. 3, pp. 173-182, 2001.

[15] I. Kyrou, G. P. Chrousos, and C. Tsigos, "Stress, visceral obesity, and metabolic complications," Annals of the New York Academy of Sciences, vol. 1083, pp. 77-110, 2006.

[16] A. Hammond and R. Levine, "The economic impact of obesity in the United States Diabetes, Metabolic Syndrome and Obesity," Targets and Therapy, vol. 3, pp. 285-295, 2010.

[17] J. G. Trogdon, E. A. Finkelstein, T. Hylands, P. S. Dellea, and S. J. Kamal-Bahl, "Indirect costs of obesity: a review of the current literature," Obesity Reviews, vol. 9, no. 5, pp. 489-500, 2008.

[18] S. Allender and M. Rayner, "The burden of overweight and obesity-related ill health in the UK," Obesity Reviews, vol. 8, no. 5, pp. 467-473, 2007.

[19] World Health Organization, World Health Report 2002, WHO, Geneva, Switzerland, 2003.

[20] R. V. Burkhauser and J. Cawley, Obesity, Disability and Movement Onto the Disability Insurance Rolls, Michigan Retirement Research Center, University of Michigan, Ann Arbor, Mich, USA, 2004.

[21] J. F. Fries, P. Spitz, G. Kraines, and H. Holman, "Measurement of patient outcome in arthritis," Arthritis and Rheumatism, vol. 23, no. 2, pp. 137-145, 1980.

[22] D. R. Ramey, J. P. Raynauld, and J. F. Fries, "The Health Assessment Questionnaire 1992: status and review," Arthritis Care and Research, vol. 5, no. 3, pp. 119-129, 1992.

[23] B. Bruce and J. F. Fries, "The Stanford Health Assessment Questionnaire: a review of its history, issues, progress, and documentation," Journal of Rheumatology, vol. 30, no. 1, pp. 167-178, 2003.

[24] S. Lillegraven and T. K. Kvien, "Measuring disability and quality of life in established rheumatoid arthritis," Best Practice and Research: Clinical Rheumatology, vol. 21, no. 5, pp. 827840, 2007.

[25] K. G. Alberti, P. Zimmet, J. Shaw, and IDF Epidemiology Task Force Consensus Group, "The metabolic syndrome-a new worldwide definition," Lancet, vol. 366, no. 9491, pp. 1059 1062, 2005.

[26] E. Krishnan, T. Sokka, A. Häkkinen, H. Hubert, and P. Hannonen, "Normative values for the Health Assessment Questionnaire disability index: benchmarking disability in the general population," Arthritis and Rheumatism, vol. 50, no. 3, pp. 953-960, 2004.

[27] S. Walter, A. Kunst, J. MacKenbach, A. Hofman, and H. Tiemeier, "Mortality and disability: the effect of overweight and obesity," International Journal of Obesity, vol. 33, no. 12, pp. 1410-1418, 2009.
[28] A. H. Mokdad, E. S. Ford, B. A. Bowman et al., "Prevalence of obesity, diabetes, and obesity-related health risk factors, 2001," JAMA, vol. 289, no. 1, pp. 76-79, 2003.

[29] A. Peeters, L. Bonneux, W. J. Nusselder, C. de Laet, and J. J. Barendregt, "Adult obesity and the burden of disability throughout life," Obesity Research, vol. 12, no. 7, pp. 11451151, 2004.

[30] S. Al Snih, K. J. Ottenbacher, K. S. Markides, Y. F. Kuo, K. Eschbach, and J. S. Goodwin, "The effect of obesity on disability vs mortality in older Americans," Archives of Internal Medicine, vol. 167, no. 8, pp. 774-780, 2007.

[31] C. A. Okoro, J. M. Hootman, T. W. Strine, L. S. Balluz, and A. H. Mokdad, "Disability, arthritis, and body weight among adults 45 years and older," Obesity Research, vol. 12, no. 5, pp. 854-861, 2004.

[32] M. Reuser, L. G. Bonneux, and F. J. Willekens, "Smoking kills, obesity disables: a multistate approach of the US health and retirement survey," Obesity, vol. 17, no. 4, pp. 783-789, 2009.

[33] Ü. Taş, A. P. Verhagen, S. M. Bierma-Zeinstra et al., "Incidence and risk factors of disability in the elderly: the Rotterdam Study," Preventive Medicine, vol. 44, no. 3, pp. 272-278, 2007.

[34] J. M. Jordan, G. Luta, J. B. Renner et al., "Self-reported functional status in osteoarthritis of the knee in a rural southern community: the role of sociodemographic factors, obesity, and knee pain," Arthritis Care and Research, vol. 9, no. 4, pp. 273-278, 1996.

[35] L. Sinigaglia, A. Nervetti, Q. Mela et al., "A multicenter cross sectional study on bone mineral density in rheumatoid arthritis. Italian Study Group on Bone Mass in Rheumatoid Arthritis," Journal of Rheumatology, vol. 27, no. 11, pp. 25822589, 2000.

[36] M. B. Yunus, S. Arslan, and J. C. Aldag, "Relationship between body mass index and fibromyalgia features," Scandinavian Journal of Rheumatology, vol. 31, no. 1, pp. 27-31, 2002.

[37] R. J. Johnson and F. D. Wolinsky, "The structure of health status among older adults: disease, disability, functional limitation, and perceived health," Journal of Health and Social Behavior, vol. 34, no. 2, pp. 105-121, 1993.

[38] A. Anandacoomarasamy, I. Caterson, P. Sambrook, M. Fransen, and L. March, "The impact of obesity on the musculoskeletal system," International Journal of Obesity, vol. 32, no. 2, pp. 211-222, 2008.

[39] H. B. Hubert, D. A. Bloch, and J. F. Fries, "Risk factors for physical disability in an aging cohort: the NHANES I Epidemiologic Followup Study," Journal of Rheumatology, vol. 20, no. 3, pp. 480-488, 1993.

[40] B. Bruce and J. F. Fries, "The Stanford Health Assessment Questionnaire: dimensions and practical applications," Health and Quality of Life Outcomes, vol. 1, article 20, 2003.

[41] F. Wolfe, K. Michaud, and V. Strand, "Expanding the definition of clinical differences: from minimally clinically important differences to really important differences. Analyses in 8931 patients with rheumatoid arthritis," Journal of Rheumatology, vol. 32, no. 4, pp. 583-589, 2005.

[42] R. T. Ackermann, S. L. Edelstein, K. M. Venkat Narayan et al., "Changes in health state utilities with changes in body mass in the diabetes prevention program," Obesity, vol. 17, no. 12, pp. 2176-2181, 2009.

[43] D. Oman, D. Reed, and A. Ferrara, "Do elderly women have more physical disability than men do?" American Journal of Epidemiology, vol. 150, no. 8, pp. 834-842, 1999.

[44] J. M. Friedmann, T. Elasy, and G. L. Jensen, "The relationship between body mass index and self-reported functional 
limitation among older adults: a gender difference," Journal of the American Geriatrics Society, vol. 49, no. 4, pp. 398-403, 2001.

[45] S. Larrieu, K. Pérès, L. Letenneur et al., "Relationship between body mass index and different domains of disability in older persons: the 3C study," International Journal of Obesity and Related Metabolic Disorders, vol. 28, no. 12, pp. 1555-1560, 2004.

[46] R. A. DeFronzo, "Pathogenesis of type 2 diabetes mellitus," Medical Clinics of North America, vol. 88, no. 4, pp. 787-835, 2004.

[47] E. Atlantis and M. Baker, "Obesity effects on depression: systematic review of epidemiological studies," International Journal of Obesity, vol. 32, no. 6, pp. 881-891, 2008.

[48] A. J. Stunkard, M. S. Faith, and K. C. Allison, "Depression and obesity," Biological Psychiatry, vol. 54, no. 3, pp. 330-337, 2003.

[49] M. S. Faith, P. E. Matz, and M. A. Jorge, "Obesity-depression associations in the population," Journal of Psychosomatic Research, vol. 53, no. 4, pp. 935-942, 2002.

[50] J. Ma and L. Xiao, "Obesity and depression in US women: results from the 2005-2006 national health and nutritional examination survey," Obesity, vol. 18, no. 2, pp. 347-353, 2010.

[51] G. Gariepy, J. Wang, A. D. Lesage, and N. Schmitz, "The longitudinal association from obesity to depression: results from the 12-year national population health survey," Obesity, vol. 18, no. 5, pp. 1033-1038, 2010.

[52] A. M. Sharma and R. F. Kushner, "A proposed clinical staging system for obesity," International Journal of Obesity, vol. 33, no. 3, pp. 289-295, 2009. 


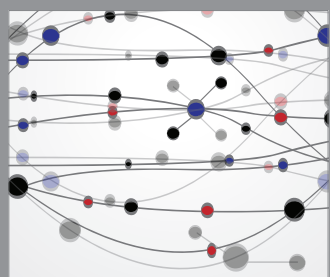

The Scientific World Journal
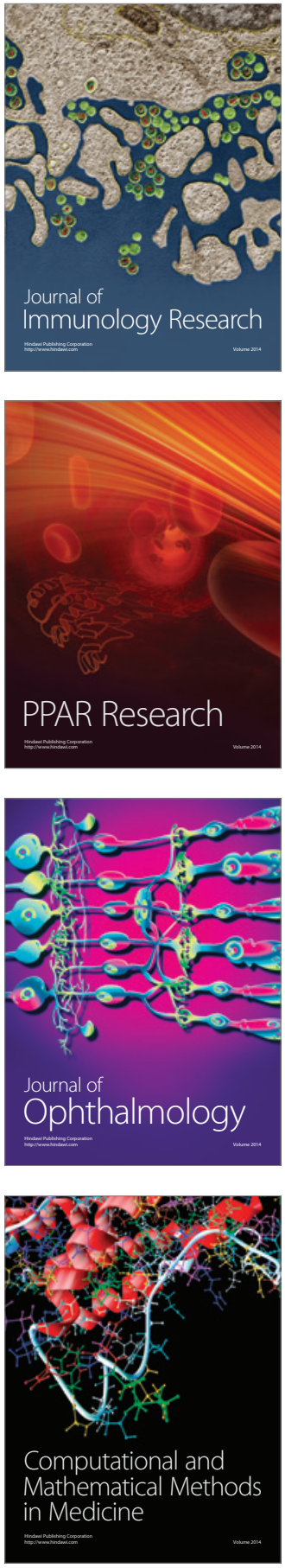

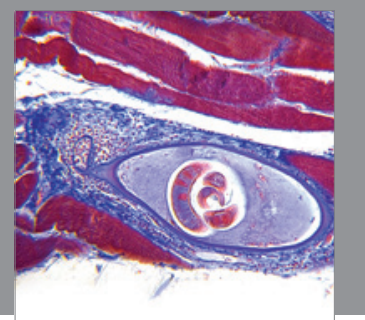

Gastroenterology

Research and Practice
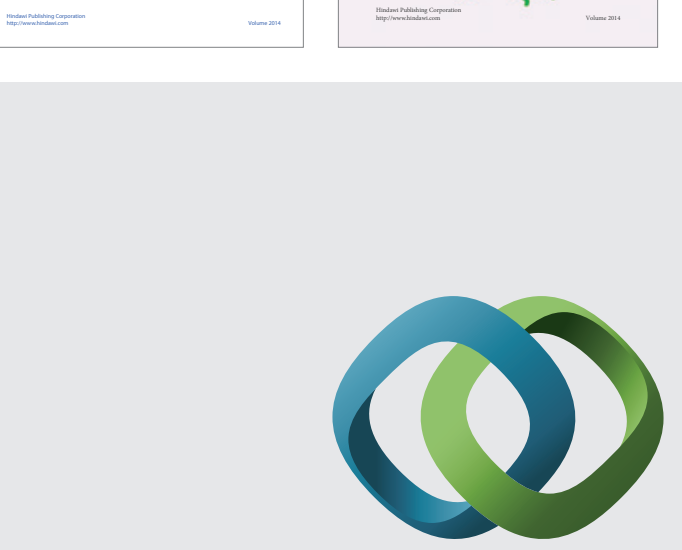

\section{Hindawi}

Submit your manuscripts at

http://www.hindawi.com
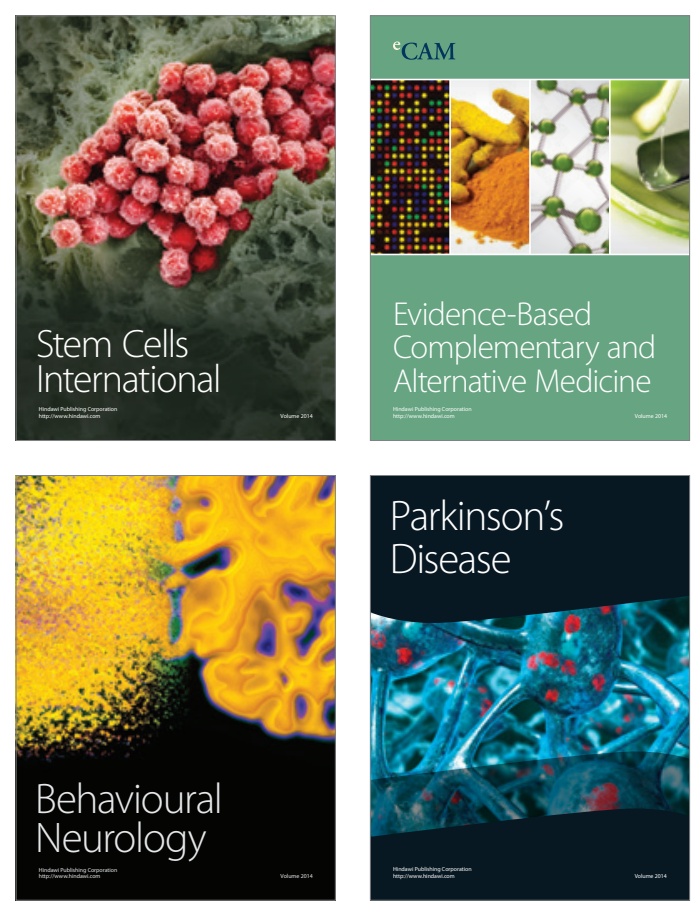

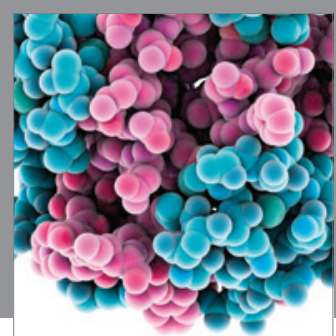

Journal of
Diabetes Research

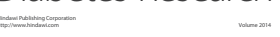

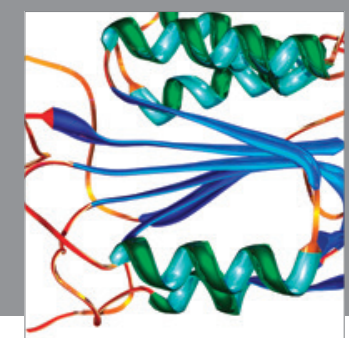

Disease Markers
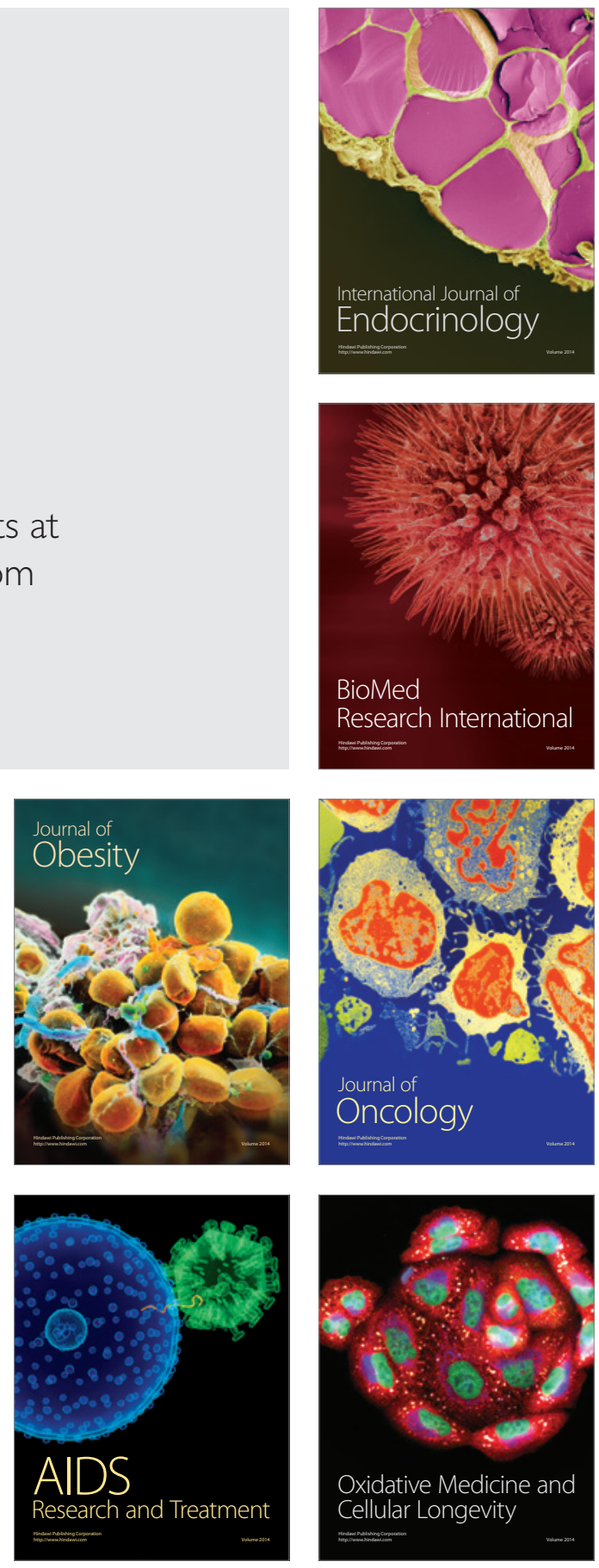